\title{
Role of diagnostic hystero-laparoscopy in the evaluation of female infertility
}

\author{
Deepa Shanmugham ${ }^{1 *}$, Nambala Divya Sahitya ${ }^{1}$, Sindhu Natarajan ${ }^{1}$, \\ Deepak Kannan Saravanany ${ }^{2}$
}

\begin{abstract}
${ }^{1}$ Department of Obstetrics and Gynecology, Aarupadai Veedu Medical College, Pondicherry, India
${ }^{2}$ MBBS Student, Aarupadai Veedu Medical College, Pondicherry, India
\end{abstract}

Received: 23 May 2019

Accepted: 01 July 2019

*Correspondence:

Dr. Deepa Shanmugham,

E-mail: drdeepabalamurugan@gmail.com

Copyright: () the author(s), publisher and licensee Medip Academy. This is an open-access article distributed under the terms of the Creative Commons Attribution Non-Commercial License, which permits unrestricted non-commercial use, distribution, and reproduction in any medium, provided the original work is properly cited.

\begin{abstract}
Background: Infertility affects about $10-15 \%$ of reproductive age couples. The main causes of infertility include male factor, ovulatory disorders, tubal factor and endometriosis. This study was conducted to determine the role of Diagnostic hystero-laparoscopy (DHL) in the evaluation of female infertility.

Methods: This study was a prospective study done in a tertiary care centre over a period of 1 year on all infertile couples. The exclusion criteria: male factor infertility, hypothyroidism, hyperprolactinemia, acute pelvic inflammatory disease. Diagnostic hysterolaparoscopy was performed in all study patients in pre ovulatory phase, under general anaesthesia. The findings were then documented and analysed.

Results: A total number of 90 patients were recruited for the study. The mean age of the patients was $28 \pm 3$ years. The mean BMI of the study patients was $25 \pm 4 \mathrm{~kg} / \mathrm{m}^{2}$. The mean duration of infertility was 5.4 years. On laparoscopy, 28 patients had polycystic ovaries (31.1\%), 4 patients had pelvic adhesions (4.4\%), 2 patients had endometriosis (2.2\%) and tubal block was identified in 10 patients (11.11\%). 10 patients had abnormal findings on hysteroscopy.

Conclusions: Hystero laparoscopy is an effective diagnostic tool in the evaluation of infertility and has to be included in basic diagnostic workup.
\end{abstract}

Keywords: Diagnostic laparoscopy, Endometriosis, Hysteroscopy, Infertility, Tubal pathology

\section{INTRODUCTION}

Worldwide, Infertility affects about $10-15 \%$ of reproductive age couples. ${ }^{1}$ According to World Health Organization (WHO), the overall prevalence of primary infertility in India is between 3.9 and $16.8 \% .^{2}$ The main causes of infertility include male factor, ovulatory disorders, tubal factor, or paratubal adhesions, endometriosis, uterine factors, systemic conditions, cervical, immunologic factors, and unexplained factors. ${ }^{3}$ Various diagnostic modalities like clinical examination, ultrasonography, hysterosalpingogram, even though being standard protocol for evaluation, fail to identify the few important causes of infertility like endometriosis, pelvic adhesions. Direct visualization of abdominal and pelvic organs in hysteroscopy and laparoscopy, allows a definite diagnosis.

Laparoscopy is the gold standard for diagnosis of tubal block and for early diagnosis of endometriosis and pelvic adhesions. ${ }^{4}$ Laparoscopy has been included in the basic fertility studies by the American fertility society in 
19235. In addition to diagnosis, diagnostic hysterolaparoscopy also provides the additional benefit of therapeutic interventions in few conditions. This study was conducted to determine the role of diagnostic hysteron-laparoscopy in the evaluation of female infertility.

\section{METHODS}

This study was a prospective study done in a tertiary care centre over a period of 1 year (January to December 2018). All patients with primary and secondary infertility in the age group of 21-35 years were enrolled for the study after obtaining informed and written consent. Patients with male factor infertility, hypothyroidism, hyper prolactinemia, acute pelvic inflammatory disease were excluded from the study.

A detailed history taking pertaining to infertility, along with general physical examination and gynaecological examination was performed in every study patient.

Basic infertility workup like pelvic ultrasonography (Trans abdominal and transvaginal-Mindray), hormone analysis which includes serum prolactin and serum thyroid stimulating hormone and partner semen analysis was done.

Each patient was admitted a day prior to the procedure and pre anaesthetic assessment was done. All patients were kept nil per oral after $10 \mathrm{pm}$ on the day before surgery. Diagnostic hysterolaparoscopy was done in the pre ovulatory period, under general anaesthesia using a Karl Storz laparoscope and hysteroscope (Karl storz, Tuttlingen, Germany).

On hysteroscopy, any abnormalities in uterine cavity like septum, fibroids, and polyps were looked for and documented. On laparoscope, inspection of all pelvic structures including fallopian tubes, ovaries, surface of uterus, pelvic peritoneum, pouch of Douglas, for any abnormalities like endometriosis, adhesions etc. was performed. Finally, chromopertubation with methylene blue dye was done for assessment of tubal patency. Any abnormal findings on hysterolaparoscopy were addressed by therapeutic intervention in the same sitting.

\section{Statistical analysis}

The findings on diagnostic hysterolaparoscopy were documented and analysed. Statistical analysis was done with SPSS software, version 16. Descriptive analysis was done as mean and percentages.

\section{RESULTS}

A total number of 90 patients were recruited for the study. Of which, 64 patients $(71.1 \%)$ had primary infertility and 26 patients $(28.8 \%)$ had secondary infertility. The demographic profile of the study patients is illustrated in Table 1. Mean age of the patients was $28 \pm 3$ years. The mean BMI of the study patients was $25 \pm 4 \mathrm{~kg} / \mathrm{m}^{2}$. The mean duration of infertility was 5.4 years, ranging from 2-10 years.

Table 1: Demographic profile of study patients.

\begin{tabular}{|ll|}
\hline Parameter & $\begin{array}{l}\text { Value/percentage } \\
(\mathbf{n}=90)\end{array}$ \\
\hline Mean age & $28 \pm 3$ years \\
\hline Mean BMI & $25 \pm 4$ years \\
\hline Duration of infertility & 5.4 years $(2-10 y e a r s)$ \\
\hline Primary infertility & $64(71.7 \%)$ \\
\hline Secondary infertility & $26(28.8 \%)$ \\
\hline
\end{tabular}

Table 2: Laparoscopic findings in study patients.

\begin{tabular}{|ll|}
\hline Pelvic pathology & Number of patients $(\%)(\mathrm{n}=90)$ \\
\hline PCOS & $28(31.1 \%)$ \\
\hline Tubal block & $10(11.1 \%)$ \\
\hline Pelvic adhesions & $4(4.4 \%)$ \\
\hline Endometriosis & $2(2.2 \%)$ \\
\hline
\end{tabular}

On laparoscopy, 28 patients had polycystic ovaries (31.1\%), 4 patients had pelvic adhesions (4.4\%), 2 patients had endometriosis $(2.2 \%)$ and tubal block was identified in 10 patients $(11.11 \%)$. These laparoscopic findings are demonstrated in Table 2.

Table 3: Hysteroscopic findings in study patients.

\begin{tabular}{|ll|}
\hline $\begin{array}{l}\text { Uterine } \\
\text { pathologies }\end{array}$ & $\begin{array}{c}\text { Number of patients }(\%) \\
(\mathrm{n}=90)\end{array}$ \\
\hline Uterine anomalies & $6(6.6 \%)$ \\
\hline Submucous fibroid & $1(2.2 \%)$ \\
\hline Uterine synechiae & $2(4.4 \%)$ \\
\hline Endometrial polyp & $1(2.2 \%)$ \\
\hline
\end{tabular}

Table 3 reveals the hysteroscopic findings in the study patients. During hysteroscopy, 6 patients (6.6\%) had uterine anomalies (septate uterus, subseptate uterus and $\mathrm{T}$ shaped uterine cavity). A submucous fibroid was observed in 1 patient $(1.11 \%)$ and an endometrial polyp was observed in 1 patient $(1.11 \%)$. Uterine synechiae was seen in 2 patients $(2.2 \%)$.

\section{DISCUSSION}

Infertility is defined as, failure to conceive after 1 year of regular unprotected intercourse. ${ }^{6}$ Tubal factor accounts for $30-40 \%$ of infertility. ${ }^{7}$ Although modalities like hysterosalpingography and saline sonosalpingography are available, for evaluation of tubal factor, they have limitations with regard to diagnostic accuracy and complications like allergy, pelvic infection, and pain and radiation exposure. ${ }^{8}$ Diagnostic hystero-laparoscopy (DHL) plays a vital role in the evaluation of the women with tubal pathology. In addition to tubal pathology, laparoscopy enlightens the consultant about any 
peritoneal disease like endometriosis. The advancement of new perspectives in assisted reproductive technology (ART) through the use of modern infertility evaluation techniques has led clinicians to reassess how infertility should best be treated. Evaluation of uterine cavity in an infertile patient in the era of Intra Uterine Insemination (IUI) and ART techniques is best accomplished by hysteroscopy. The added benefit of this procedure, is "see and treat": Therapeutic intervention can be done at the same sitting, by the surgeon. This study was done to analyse the role of DHL in diagnosis of pelvic pathology in infertile women.

The mean age of the patients was 28 years. The probable reason being late marriages, delayed seeking of the care at a tertiary care centre by the infertile couple. Similar age group patients were observed in other studies. In a study by Mehta et al, the patients in secondary infertility group were slightly elder compared to primary group (28.8 \pm 3.7$).{ }^{9}$ A study by Nanaware et al shows similar findings, with maximum number of infertility cases belonging to the age group 26-30 years. ${ }^{10}$ Similar results were seen in a study by Chanu et al, where the mean age of patients with primary infertility was $27.2 \pm 2.6$ years. ${ }^{11}$

Majority of the patients had presented with primary infertility $(71.1 \%)$ as expected. The average duration of infertility in our study was 5.4 years. Similar finding were seen in a study by Mehta et al, where the duration of infertility was $4.8 \pm 3.2$ years. ${ }^{9}$ A study by Ashok Kumar K et al, shows similar results, with a mean duration of 5.9 years. $^{12}$

According to World Health Organization, malnutrition, pelvic tuberculosis and pelvic infections leading to tubal blockage is still the major cause of infertility. ${ }^{13}$ It is found that $39-41 \%$ of tubal factor infertility is associated with tuberculosis, which is more common in developing countries. ${ }^{14}$ Incidence of endometriosis has risen in the past few years due to the increase in use to diagnostic laparoscopic techniques. Laparoscopy is the standard method to visually identify endometriotic lesions under magnification, within the pelvis and peritoneal cavity and for performing targeted biopsies for histological collaboration. ${ }^{15,16}$ However early diagnosis and intervention in endometriosis can help improve fertility outcomes.

In the present study, on laparoscopic evaluation, majority of the patients had polycystic ovaries $(31.1 \%)$, followed by tubal pathology $(11.1 \%)$ and endometriosis, since PCOS is the most common cause of infertility in recent years. ${ }^{17}$ The findings of our study are comparable to various other studies. ${ }^{9-12,18-21}$ The prospective study by Boricha et al, in 50 infertile couples found polycystic ovarian syndrome as the commonest cause of infertility in both primary and secondary infertility. ${ }^{18}$ In a study by Jain et al, on 203 women on whom laparoscopy for the evaluation of infertility was done, it was observed that tubal disease was the responsible factor in $62.8 \%$ women with primary infertility and $54.8 \%$ women with secondary infertility followed by pelvic adhesions in $33 \%$ and $31.5 \%$, ovarian factor in $14 \%$ and $8.5 \%$, pelvic endometriosis in $9.9 \%$ and $6.1 \%$ women respectively. ${ }^{19}$

Mehta et al, reported in her prospective hospital based study on 300 patients, over 2 years, that Endometriosis and adnexal adhesions were the most common abnormalities detected in laparoscopy in primary and secondary infertility groups respectively. ${ }^{9}$ In a retrospective study on 85 patients, by Nanaware et al, Tubal pathology (43.2\%) and pelvic Adhesion (40\%) were the most common abnormalities detected in laparoscopy in both primary and secondary infertility. ${ }^{10}$

A retrospective study on 151 patients by Chanu et al shows that the most common abnormalities found during laparoscopy in both the primary and secondary infertility group were features of PID (adnexal adhesion and hydrosalpinx). ${ }^{11}$ In a prospective study done on 50 female infertility patients, by Ashok Kumar K, abnormal laparoscopic findings were detected in 41 (82\%) cases. Tubal factor was seen in $14(28 \%)$ cases, 11 (22\%) cases had endometriosis, $10(20 \%)$ cases had ovarian factor, 4 $(8 \%)$ cases had pelvic adhesions and 2 (4\%) had fibroid uterus. $^{12}$

In retrospective study on the role of diagnostic hysterolaparoscopy in the evaluation of infertility on 300 patients by Nayak et al, the most common laparoscopic abnormality was endometriosis (14\%) and adnexal adhesion (12\%) in primary and secondary infertility patients. $^{20}$ Kabadi et al's retrospective study on 94 patients showed the most common abnormality on laparoscopy as PCOS $(20.8 \%){ }^{21}$

Anomalies within the uterine cavity play an important role in fertility, because they can prevent implantation. The uterine disorders most often observed during hysteroscopy and implicated in infertility are septae, synechiae, polyps, submucous myomas, adenomyosis, endometritis, lesions of uterotubal junction and anomalies of cervical canal. ${ }^{22}$ This procedure also allows resection of submucous myomas, polyps, septae and adhesiolysis, which can improve the fertility of the patient.

Septate uterus was the most common intrauterine abnormality in our study similar to other studies, which was undiagnosed by ultrasound., $9,10,20$ Hysteroscopy revealed an endometrial polyp in a patient who was diagnosed to have thickened endometrium on ultrasonography. The next common intrauterine pathology was synechiae $(2.2 \%)$. similar to observation made by Nanaware et al. ${ }^{10}$ The synechiae formation is more common in secondary infertility women because of this group had previous history of dilatation and curettage. A retrospective analysis on 257 women by Geetika Jain et al, showed that, most common abnormality in hysteroscopy was uterine synechiae. ${ }^{19}$ Table 4 shows the comparison between present study and 
the other studies. Only 1 patient had submucosal fibroid in our study. A study by Mehta et al, describes that following septate uterus, the most common abnormalities on hysteroscopy were myomas and polyps. Proposed mechanisms by which myomas might adversely affect fertility include cornual myomas that involve or compress the interstitial segment of the tube, dysfunctional uterine contractility interfering with sperm transport or embryo implantation, and poor regional blood flow resulting in focal endometrial attenuation or ulceration. ${ }^{9}$

Table 4: Review of literature of hystero laparoscopic findings in infertile patients.

\begin{tabular}{|c|c|c|c|c|c|c|}
\hline \multirow[t]{2}{*}{ Study } & \multirow[t]{2}{*}{$\begin{array}{l}\text { No. of } \\
\text { patients }\end{array}$} & \multicolumn{4}{|c|}{ Laparoscopic findings } & \multirow[t]{2}{*}{ Hysteroscopic findings } \\
\hline & & PCOS & Tubal pathology & Endometriosis & Others & \\
\hline Nayak PK et al ${ }^{20}$ & 300 & $22 \%$ & $12 \%$ & $14 \%$ & - & $\begin{array}{l}\text { Septum }(10 \%) \\
\text { Polyp }(5 \%) \\
\text { Fibroid }(3 \%) \\
\text { Synechiae }(1 \%)\end{array}$ \\
\hline Kabadi et $\mathrm{al}^{21}$ & 94 & $20.8 \%$ & $7.7 \%$ & $5.4 \%$ & $18.1 \%$ & - \\
\hline Geetika Jain et al ${ }^{19}$ & 203 & $6.4 \%$ & $59.6 \%$ & $8.3 \%$ & - & - \\
\hline Chanu et al ${ }^{11}$ & 151 & $20 \%$ & $4.6 \%$ & $9.3 \%$ & $6 \%$ & $\begin{array}{l}\text { Synechiae }(3.3 \%) \\
\text { Fibroid, polyp and } \\
\text { septum }(1.99 \% \text { each })\end{array}$ \\
\hline Mehta et $\mathrm{al}^{9}$ & 300 & $26.1 \%$ & $12 \%$ & $14 \%$ & - & $\begin{array}{l}\text { Septum }(10 \%), \text { polyp } \\
(5 \%), \text { Fibroid }(3 \%), \\
\text { synechiae }(0.1 \%)\end{array}$ \\
\hline Ashok Kumar ${ }^{12}$ & 50 & $20 \%$ & $14 \%$ & $22 \%$ & $12 \%$ & \\
\hline Nanaware et al ${ }^{10}$ & 85 & - & $43.3 \%$ & - & $40 \%$ & $\begin{array}{l}\text { Septum and synechiae } \\
\text { (5.5\% each) }\end{array}$ \\
\hline Present study & 90 & $31.1 \%$ & $11.1 \%$ & $2.2 \%$ & $13.2 \%$ & $\begin{array}{l}\text { Septum }(6.6 \%), \\
\text { Synechiae }(4.4 \%), \\
\text { Fibroid and polyp } \\
(2.2 \% \text { each) }\end{array}$ \\
\hline
\end{tabular}

\section{CONCLUSION}

Hystero laparoscopy is an effective diagnostic tool in the evaluation of infertility and has to be included in basic diagnostic workup with the added advantage of correction of the abnormal finding therapeutically at the same sitting enhancing the fertility.

\section{ACKNOWLEDGMENTS}

Authors would like to thank the Dean, the Institutional Research Committee and the management of Aarupadai Veedu Medical College for their motivation and support.

Funding: No funding sources Conflict of interest: None declared Ethical approval: Not required

\section{REFERENCES}

1. Boivin J, Bunting L, Collins JA, Nygren KG. International estimates of infertility prevalence and treatment-seeking: Potential need and demand for infertility medical care. Hum Reprod. 2007;22:150612.

2. Infecundity, infertility, and childlessness in developing countries. DHS Comparative Reports No. 9. Calverton, Maryland, USA: ORC Macro and the World Health Organization; 2004.

3. Berek JS. Berek and Novak's Gynaecology. 15th Ed. Lippincott William's and Wilkins; 2012.

4. Birmingham Al. Investigation of the infertile couple. Am Fertil Soc.1992.

5. Shanmugham D, Vidhyalakshmi RK, Varghese J. Evaluation of tubal patency in infertile patients with saline infusion sonosalpingogram. Int $\mathrm{J}$ Reprod Contracept Obstet Gynecol. 2018;7:7:2590-5.

6. Borght MV, Wyns C. Fertility and infertility: Definition and epidemiology. Clin Biochem. 2018;62:2-10.

7. Laurence AM, Michael RS. Infertility evaluation and treatment. In: Imaging of the Reproductive Tract in Infertile Women: Hysterosalpingography, Ultrasonography and Magnetic Resonance Imaging, Chapter 23. WB Saunders Company; 1995:300-3. 
8. Balasch J. Investigation of the infertile couple: investigation of the infertile couple in the era of assisted reproductive technology: a time for reappraisal. Hum Reprod. 2000;15(11):2251-7.

9. Modi AP, Raval BM, Munshi SP, Patel SB, Dedharotiya SM, et al. Role of diagnostic hysterolaparoscopy in the evaluation of infertility. Int J Reprod Contracept Obstet Gynecol. 2016;5(2):43740.

10. Nanaware SS, Saswade M, Shende PN, Gaikwad P, Mahana S, Kirane A. Role of hysterolaparoscopy in the evaluation of female infertility in tertiary care centre. Int J Contem Med Res. 2016;3(10):3063-5.

11. Chanu SM, Rudra Pal GS, Panda S, Singh AS, Diagnostic hysterolaparoscopy for evaluation of infertility: Our experience in a tertiary Care Hospital. J Hum Reprod Sci. 2018;11:19-23.

12. Ashok Kumar K, Priyanka Jogi Y, Bharathi A. Diagnostic laparoscopy in the evaluation of female factor infertility. Int $\mathbf{J}$ Reprod Contracept Obstet Gynecol. 2017;6:383-7.

13. Mehmood S. An audit of diagnostic laparoscopies for infertility. J Surg Pak. 2003;8:8-10.

14. Goel G, Khatuja R, Radhakrishnan G, Agarwal R, Agarwal S, Kaur I. Role of newer methods of diagnosing genital tuberculosis in infertile women. Indian J Pathol Microbiol. 2013;56:155-7.

15. Mettler L, Schollmeyer T, Lewin A. Accuracy of laparoscopic diagnosis of endometriosis. J Society Laparoend Diag Endometrio. 2003;7(3):290.

16. Martin DC, Hubert GD, Vender Zwang R. Laparoscopic appearance of peritoneal endometriosis. Fertility Steril. 1989;51:63-7.
17. Shanmugham D, Vidhyalakshmi RK, Shivamurthy HM. The effect of baseline serum luteinizing hormone levels on follicular development, ovulation, conception and pregnancy outcome in infertile patients with polycystic ovarian syndrome. Int $\mathbf{J}$ Reprod Contracept Obstet Gynecol. 2017;7(1):31822.

18. Boricha YG, Sharma RK, Boricha BG, Mhapankar S, Chaterjee A, Narshetty J. Laparoscopy in 50 infertile couples: prospective study. Int J Med Clin Res. 2011;2:63-6.

19. Jain G, Khatuja R, Juneja A, Mehta S. Laparoscopy: as a first line diagnostic tool for infertility evaluation. J Clin Diagnost Res. 2014;8(10):OC01-OC02.

20. Nayak PK, Mahapatra PC, Mallick J, Swain S, Mitra $\mathrm{S}$, Sahoo J. Role of diagnostic hystero-laparoscopy in the evaluation of infertility: a retrospective study of 300 patients. J Hum Reprod Sci. 2013;6:32-4.

21. Kabadi YM, Harsha B. Hysterolaparoscopy in the Evaluation and Management of Female Infertility. J Obstet Gynaecol India. 2016;66(Suppl 1):478-81.

22. Merviel P, Mergui JL, Sanames S, Antone JM, SalotBaroux, Uzan S. Role of hysteroscopy in diagnosis and treatment of infertility. Europe PHC. 2000;29(23):1302-10.

Cite this article as: Shanmugham D, Sahitya ND, Natarajan S, Saravanany DK. Role of diagnostic hystero-laparoscopy in the evaluation of female infertility. Int J Reprod Contracept Obstet Gynecol 2019;8:3156-60. 